\title{
Incidence of tropical spastic parapesis/ HTLV-1 associated myelopathy/ (TSP/HAM) in patients followed in a Reference center in Salvador, Brasil
}

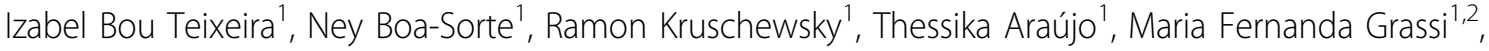 \\ Bernardo Galvão-Castro ${ }^{1,2^{*}}$
}

From 17th International Conference on Human Retroviruses: HTLV and Related Viruses

Trois Ilets, Martinique. 18-21 June 2015

It is estimated that currently 5 to 10 million people are infected with HTLV-1 worldwide. In Brazil, Salvador is the city with the highest prevalence of HTLV-1 (2\% in women and $1.2 \%$ in men). Tropical spastic paraparesis/ HTLV associated myelopathy (TSP/HAM) is an insidious and disabling chronic neurological disease. The incidence of TSP/HAM varies in different geographical regions with low rate in Japan and Caribbean islands and higher in Minas Gerais, Brazil. The incidence of TSP/HAM among patients attending the CHTLV in Salvador/BA, from 22 to 2013 was estimated. The outcome of interest was the evolution from asymptomatic status for TSP/HAM diagnosis, which was based on the Belem criteria. The follow-up for individuals that remained asymptomatic was the time between the year of the last medical consultation and the year of the HTLV-1 serological diagnosis and for those that developed TSP/HAM the time between the year of diagnosis of TSP/HAM and the year of HTLV-1 serological diagnosis. The exclusion criteria were a diagnosis of TSP/ HAM at the first medical consultation, records with incomplete data and TSP/HAM possible diagnosis. From a sample of 243 patients, 91 were included. Two patients developed TSP/HAM definite and four had TSP/HAM probable diagnosis. The incidence density of TSP/HAM definite was 6.9 and 13 per 1,0 HTLV-1 infected individuals per year, respectively. The cumulative incidence to TSP/HAM definite was $2.29 \%$ while to TSP/HAM probable was $4.39 \%$. The incidence rate found herein was higher than that observed in previous

\footnotetext{
* Correspondence: bgalvao@bahiana.edu.br

${ }^{1}$ Centro Integrativo e Interdisciplinar de HTLV (CHTLV), Escola Bahiana de Medicina e Saúde Pública; Salvador-Bahia-Brazil

Full list of author information is available at the end of the article
}

studies in Japan and Caribbean, however, similar to that reported in Brazil. More accurate cohort studies should be conducted to measure the actual risk of developing this disease.

\section{Authors' details}

${ }^{1}$ Centro Integrativo e Interdisciplinar de HTLV (CHTLV), Escola Bahiana de Medicina e Saúde Pública; Salvador-Bahia-Brazil. "Laboratório Avançado de Saúde Pública, Centro de Pesquisas Gonçalo Moniz, Fundação Oswaldo Cruz, Salvador, Bahia, Brasil.

Published: 28 August 2015

doi:10.1186/1742-4690-12-S1-P35

Cite this article as: Teixeira et al:: Incidence of tropical spastic parapesis/ HTLV-1 associated myelopathy/ (TSP/HAM) in patients followed in a Reference center in Salvador, Brasil. Retrovirology 2015 12(Suppl 1):P35.

\section{Submit your next manuscript to BioMed Central and take full advantage of: \\ - Convenient online submission \\ - Thorough peer review \\ - No space constraints or color figure charges \\ - Immediate publication on acceptance \\ - Inclusion in PubMed, CAS, Scopus and Google Scholar \\ - Research which is freely available for redistribution

